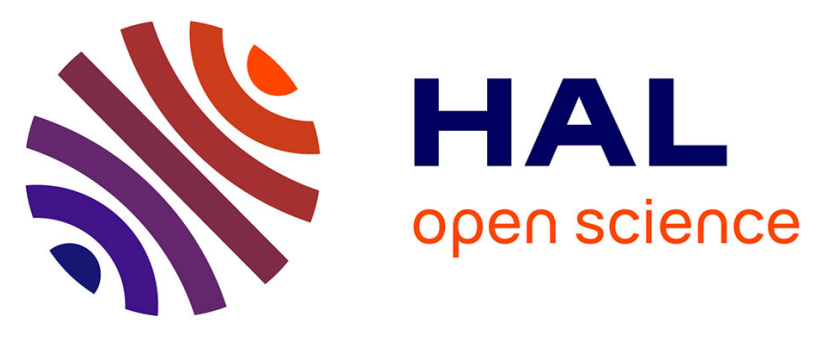

\title{
Environmental Science and Pollution Research Novel green PVA-fullerenol mixed matrix supported membranes for separating water-THF mixtures by pervaporation
}

Anastasia Penkova, Maria Dmitrenko, Sergey S Ermakov, Alexander Toikka, Denis Roizard

\section{To cite this version:}

Anastasia Penkova, Maria Dmitrenko, Sergey S Ermakov, Alexander Toikka, Denis Roizard. Environmental Science and Pollution Research Novel green PVA-fullerenol mixed matrix supported membranes for separating water-THF mixtures by pervaporation. Environmental Science and Pollution Research, 2017, 25 (21), pp.20354-20362. 10.1007/s11356-017-9063-9 . hal-02398757

\section{HAL Id: hal-02398757 https://hal.science/hal-02398757}

Submitted on 7 Dec 2019

HAL is a multi-disciplinary open access archive for the deposit and dissemination of scientific research documents, whether they are published or not. The documents may come from teaching and research institutions in France or abroad, or from public or private research centers.
L'archive ouverte pluridisciplinaire $\mathbf{H A L}$, est destinée au dépôt et à la diffusion de documents scientifiques de niveau recherche, publiés ou non, émanant des établissements d'enseignement et de recherche français ou étrangers, des laboratoires publics ou privés. 


\section{Environmental Science and Pollution Research Novel green PVA-fullerenol mixed matrix supported membranes for separating water- THF mixtures by pervaporation}

Environ Sci, Pollut Res, Anastasia Penkova, Maria Dmitrenko, Sergey Ermakov, Alexander Toikka, Denis Roizard

\section{To cite this version:}

Environ Sci, Pollut Res, Anastasia Penkova, Maria Dmitrenko, Sergey Ermakov, et al.. Environmental Science and Pollution Research Novel green PVA-fullerenol mixed matrix supported membranes for separating water- THF mixtures by pervaporation. Environmental Science and Pollution Research, Springer Verlag, 2017, 25 (21), pp.20354-20362. 10.1007/s11356-017-9063-9 . hal-02398757

\section{HAL Id: hal-02398757 \\ https://hal.archives-ouvertes.fr/hal-02398757}

Submitted on 7 Dec 2019

HAL is a multi-disciplinary open access archive for the deposit and dissemination of scientific research documents, whether they are published or not. The documents may come from teaching and research institutions in France or abroad, or from public or private research centers.
L'archive ouverte pluridisciplinaire HAL, est destinée au dépôt et à la diffusion de documents scientifiques de niveau recherche, publiés ou non, émanant des établissements d'enseignement et de recherche français ou étrangers, des laboratoires publics ou privés. 


\title{
Novel green PVA-fullerenol mixed matrix supported membranes for separating water-THF mixtures by pervaporation
}

\author{
Anastasia V. Penkova $^{1}$ (D) Maria E. Dmitrenko ${ }^{1} \cdot$ Sergey S. Ermakov $^{1} \cdot$ \\ Alexander M. Toikka ${ }^{1} \cdot$ Denis Roizard ${ }^{2}$
}

Received: 30 December 2016 / Accepted: 18 April 2017

\begin{abstract}
This study focuses first on the preparation of mixed matrix supported membranes of polyvinyl alcohol (PVA) and low-hydroxylated fullerenol $\mathrm{C}_{60}(\mathrm{OH})_{12}$ used to create water selective membranes and then on their pervaporation properties for the separation of water-THF mixtures. These novel supported PVA membranes containing nano-carbon particles were prepared to reach high membrane performance for further integration in a dehydration process, such as distillation coupled to pervaporation. The separation of water-THF mixtures was performed with the supported membranes over a wide range of water concentrations in the feed mixture, i.e., from the azeotrope range up to $30 \mathrm{wt} \%$, to evaluate the performance and stability of the thin active layer. SEM was used to visualize the internal morphology of the membrane. The influence of temperature on the transport properties was also investigated. All the membranes were highly water selective and stable up to $30 \mathrm{wt} \%$ water in the feed. The best compromise of transport properties was obtained for the $\mathrm{C}_{60}(\mathrm{OH})_{12}(5 \%)$-PVA supported composite membrane: a permeate enrichment of $99.3 \pm 0.3 \mathrm{wt} \%$ water and a flux of $0.25 \pm 0.02 \mathrm{~kg} /\left(\mathrm{m}^{2} \mathrm{~h}\right)$ for the separation of a mixture containing $5.7 \mathrm{wt} \%$ water and $94.3 \mathrm{wt} \%$ tetrahydrofuran (THF) at $30{ }^{\circ} \mathrm{C}$. Considering its water stability, this supported membrane with a dense layer thinner than $2 \mu \mathrm{m}$ appears promising
\end{abstract}

Responsible editor: Santiago V. Luis

Anastasia V. Penkova

a.penkova@spbu.ru

1 Institute of Chemistry, St. Petersburg State University, Universitetsky pr. 26, Peterhof, Saint Petersburg 198504, Russia

2 Laboratoire Réactions et Génie des Procédés, CNRS, Université de Lorraine, ENSIC, 1 rue Granville, 54000 Nancy, France for use in hybrid industrial processes to upgrade solvents with a smaller environmental footprint than conventional methods.

Keywords Tetrahydrofuran · Dehydration · Polyvinyl alcohol $\cdot$ Fullerenol $\cdot$ Membrane $\cdot$ Pervaporation

\section{Introduction}

Membrane processes are environmentally friendly methods that can significantly improve the design and development of new energy consumption processes, which are so important in modern societies. Membrane technology offers an energyefficient alternative to traditional industrial separation processes, and in some industries, membrane processes have become the standard for given applications. However, there are still significant improvements that need to be made to improve membrane performance, to avoid manufacturing defects and to decrease the module costs at full production scale. Thus, it is critical to continue investigations at the lab scale to improve membrane separation and to enlarge the scope of industrial applications.

This study investigates the separation of an industrially important mixture of water and tetrahydrofuran (THF) by pervaporation. Pervaporation is a membrane process that is able to induce the molecular separation of azeotropes without adding any chemicals and using less energy than distillation.

THF is an industrial solvent used in the polymer and pharmaceutical industries due to its high solvation power for a wide range of nonpolar and polar chemical compounds. The manufacturing of many chemicals requires THF, which is quite expensive; thus, the problem of THF recovery and careful purification is very important. THF recycling from the waste solvent streams by dehydration will thus help to decrease the process cost and to decrease environmental impacts. 
The dehydration of THF is difficult because this solvent forms an azeotrope with water. This study focuses on a reference water-THF mixture with THF and water contents of $94.3 \mathrm{wt} \%$ and $5.7 \mathrm{wt} \%$, respectively, as previously investigated (Koczka et al. 2007); this mixture forms an azeotrope at $64.9^{\circ} \mathrm{C}$. Therefore, due to the thermodynamic limit, conventional distillation cannot separate this mixture in a single step, which in turn induces a high energy cost. Currently, the most commonly used methods for obtaining anhydrous THF is extractive distillation using 1,4-butanediol or 1,2-propanediol as entrainers (Wilkes et al. 1990; Xu and Wang 2006), molecular sieves (Bradley et al. 2010), and the application of different desiccants (e.g., $\mathrm{KOH}, \mathrm{NaOH}$, silica, and alumina). One possible way to upgrade this separation is by using pervaporation in a hybrid process with conventional distillation. Pervaporation can separate the low molecular weight substances via a distinct mechanism, i.e., sorption and diffusion; hence, this separation process does not require any additional additives to break the azeotropes (Truong et al. 2013; Servel et al. 2014; Mahdi et al. 2015). A recent review of the separation of a water-THF mixture by pervaporation was published by P.D. Chapman et al. (Chapman et al. 2008). Based on this review, the most selective membrane for this mixture separation was a membrane based on polyvinyl alcohol $(\mathrm{PVA}) /$ chitosan $(20: 80)$ (selectivity $(\alpha)=4203$; flux $(J)=0.098 \mathrm{~kg} /\left(\mathrm{m}^{2} \mathrm{~h}\right)$ ), and the most permeable membrane was based on microporous silica (ECN) (flux $(J)=5.82 \mathrm{~kg} /$ $\left(\mathrm{m}^{2} \mathrm{~h}\right)$; selectivity $\left.(\alpha)=147\right)$.

In previous studies, dense membranes based on the PVAfullerenol $\mathrm{C}_{60}(\mathrm{OH})$ n composite $(n=12,22-24)$ (Penkova et al. 2014; Penkova et al. 2015; Penkova et al. 2016) with thicknesses close to $45 \mu \mathrm{m}$ were developed. However, these membranes are far too thick to be used as industrial membranes. The best transport properties for the dehydration of different types of binary and multicomponent systems via pervaporation were found with the chemically cross-linked PVA membrane containing $5 \mathrm{wt} \%$ fullerenol. Fullerenol is a water-soluble particle that has good compatibility with PVA and excellent dispersion in PVA aqueous solutions (e.g., up to $5 \mathrm{wt} \%$ to the weight of dry PVA). Additionally, lowhydroxylated fullerene is not expensive; it was obtained via the alkaline hydrolysis of fullerene bromide instead of the method of preparing $\mathrm{C}_{60}(\mathrm{OH})_{22-24}$ from $\mathrm{C}_{60}$.

In order to improve membrane efficiency for industrial applications, the selective layer has to be decreased. This can be done by casting the polymer solution onto a porous support to obtain a composite membrane with a thin active layer. Some intrinsic limitations to the strategy exist relating to the decrease in the active layer thickness that necessitated a brief recall. First, an obvious risk exists when introducing defects and excessively decreasing the mechanical properties. However, at the industrial level, membranes with an active layer thickness as low as $0.1 \mu \mathrm{m}$ are already available. Thus, the main limitations are linked to hydrodynamics and engineering issues; indeed, at low feed concentrations, concentration polarization as well as temperature polarization will occur more easily when composite membranes with ultra-thin active layers are used.

Therefore, the aim of the work was to develop novel supported membranes with a thin cross-linked active layer of PVA and PVA-fullerenol to obtain both a very high water selectivity and the high level of permeance required for industrial applications. Additionally, the application of a selective layer based on water-soluble components, such as PVA and fullerenol, in supported membrane preparation could lead to "greener" membranes that can be used in the design of energy-efficient processes for the recovery of THF with a hybrid membrane process.

Most of the papers published on membrane improvement focus only on creating new membrane materials and rarely analyze them in conditions similar to those for industrial operations. To evaluate membrane materials in conditions similar to real industrial conditions, factors such as a wide range of feed mixture concentrations, creation of supported membranes, feasibility of a thin selective layer, and membrane stability should also be considered. Different parameters were investigated to study the transport properties of these novel composite membranes: (1) the influence of temperature (30, $50,60^{\circ} \mathrm{C}$ ) was analyzed because industrial processes can use variable sources of waste heat streams, and temperature can also increase membrane performance; a maximum temperature of $60^{\circ} \mathrm{C}$ was chosen because the boiling temperature of a water-THF azeotrope mixture is $64.9^{\circ} \mathrm{C}$; (2) the separation of the water-THF mixture was performed with a wide range of water concentrations in the feed mixture (e.g., up to $30 \mathrm{wt} \%$ ) to evaluate membrane stability and performance with a relatively high water concentration in order to determine the potential applications of these supported membranes in a real industrial process. To avoid a high energy demand due to distillation conditions too near the azeotrope point, the outlet stream of the distillation column should have a water content that much greater than $5 \%$ (e.g., up to $30 \mathrm{wt} \%$ ) to optimize the overall separation cost.

\section{Material and methods}

\section{Material}

PVA with a molecular weight of $141 \mathrm{kDa}$ purchased from ZAO LenReaktiv (certificate of analysis № 553041-3013, date of manufacture 09.2011) was used as the membrane material. A hydrophilic porous membrane based on aromatic polysulfoneamide (UPM, pore size 200A) was purchased from "Vladipor" (Russia) and used as the membrane support. THF was purchased from "Sigma-Aldrich" (France), and 
maleic acid (MA) was purchased from "Vecton" (Russia). Fullerenol $\mathrm{C}_{60}(\mathrm{OH})_{12}$ (Fullerene Technologies, Russia) was used for PVA modification.

\section{Membrane preparation}

\section{Dense membranes}

Chemically cross-linked dense PVA and PVA-fullerenol membranes were prepared with $35 \mathrm{wt} \% \mathrm{MA}$ ( $w / w$ with respect to the weight of the polymer) using a solution casting method and dried using solvent evaporation with a subsequent thermal treatment at $110{ }^{\circ} \mathrm{C}$ for 120 min (Penkova et al. 2014). The polymer was cross-linked by treatment with and without the addition of fullerenol in both cases.

\section{Supported membranes}

The formation of the thin selective layer in the supported membrane was achieved by casting 2 wt $\%$ PVA aqueous solution containing $35 \mathrm{wt} \%$ maleic acid with and without fullerenol $(1,2$, and $5 \% \mathrm{w} / \mathrm{w}$ with respect to the weight of the polymer) onto the surface of the UPM support and drying at room temperature to form a selective layer with a thickness of $1.5 \pm 0.3 \mu \mathrm{m}$, as determined by scanning electron microscopy (SEM) measurements. Cross-linking of the selective layer was achieved by heating the membrane to $110^{\circ} \mathrm{C}$ for $120 \mathrm{~min}$. The membranes with thinner selective layers had poor selectivity.

The maximum concentration of fullerenol was limited to $5 \mathrm{wt} \%$ because fullerenol concentrations exceeding $5 \mathrm{wt} \%$ resulted in a poor dispersion of fullerenol in solution, and these membranes had lower mechanical properties.

The names of the prepared membranes are presented in Table 1.

\section{Scanning electron microscopy}

SEM micrographs of the fracture surfaces perpendicular to the membrane plane were obtained using a Zeiss Merlin SEM. The homogeneous membranes were submerged in liquid nitrogen for $5 \mathrm{~min}$ and fractured perpendicular to the surface. The prepared specimens were observed using SEM at $1 \mathrm{kV}$.

\section{Pervaporation experiments}

The transport properties were studied using a laboratory cell at 30, 50, and $60^{\circ} \mathrm{C}$ (Fig. 1).

A downstream pressure of $<10^{-2} \mathrm{kPa}$ was maintained using a vacuum pump and was controlled by a pressure gauge. The permeate was collected in a liquid nitrogen trap, weighed, and then analyzed via gas chromatography. The gas chromatograph used (SHIMADZU GC-2010) was equipped with a HP-PLOT/ $\mathrm{U}$ column and a thermal conductivity detector to perform a quantitative analysis of the feed and the permeate composition.

The membrane permeation flux $J\left(\mathrm{~kg} / \mathrm{m}^{2} \mathrm{~h}\right)$ was determined to be the amount of liquid transported through a unit of the membrane area per hour and was calculated as

$J=\frac{W}{A \times t}$

where $W(\mathrm{~kg})$ is the weight of the liquids that permeated the membrane, $A\left(\mathrm{~m}^{2}\right)$ is the effective membrane area, and $t(\mathrm{~h})$ is the measurement time.

The membrane partial flux $j_{i}\left(\mathrm{~kg} / \mathrm{m}^{2} \mathrm{~h}\right)$ was calculated as

$j_{i}=J \times y_{i}$

where $J$ is the permeation flux and $y_{i}$ is the weight fraction of the water or THF in the permeate.

The separation factor $\beta$ is defined by the equation:

$\beta=\frac{y_{w} / y_{\mathrm{THF}}}{x_{w} / x_{\mathrm{THF}}}$

where $y_{w}$ and $y_{\mathrm{THF}}$ are the weight fractions of the water and THF in the permeate, respectively, and $x_{w}$ and $x_{\mathrm{THF}}$ are the weight fractions of the water and THF in the feed, respectively.

The selectivity for the vapor-liquid equilibrium (VLE) is calculated as

$\alpha^{\mathrm{VLE}}=\frac{y^{\mathrm{vapor}}{ }_{w} / y^{\mathrm{vapor}} \mathrm{THF}}{x_{w} / x_{\mathrm{THF}}}$
Table 1 Prepared PVA membrane samples

\begin{tabular}{llll}
\hline Membrane name & Type & $\begin{array}{l}\text { Thickness of the } \\
\text { dense layer }(\mu \mathrm{m})\end{array}$ & Weight content of cross-linker/modifier \\
\hline PVA-0-dense $^{\mathrm{a}}$ & Dense & 40 & $35 \%$ maleic acid \\
PVA-5-dense & Dense & 40 & $35 \%$ maleic acid $/ 5 \%$ fullerenol \\
PVA-0-sup & Supported & 1.5 & $35 \%$ maleic acid \\
PVA-1-sup & Supported & 1.5 & $35 \%$ maleic acid $/ 1 \%$ fullerenol \\
PVA-2-sup & Supported & 1.5 & $35 \%$ maleic acid $/ 2 \%$ fullerenol \\
PVA-5-sup & Supported & 1.5 & $35 \%$ maleic acid $/ 5 \%$ fullerenol \\
\hline
\end{tabular}

a To simplify the membrane notation, " 0 or 1 or... 5 " correspond to the weight $\%$ of fullerenol 
Fig. 1 Experimental pervaporation setup. (1) thermostated feed with stirring, 2 membrane, 3 permeate, 4 cold trap, $\mathbf{5}$ vacuum pump, and $\mathrm{P}$ atmospheric pressure

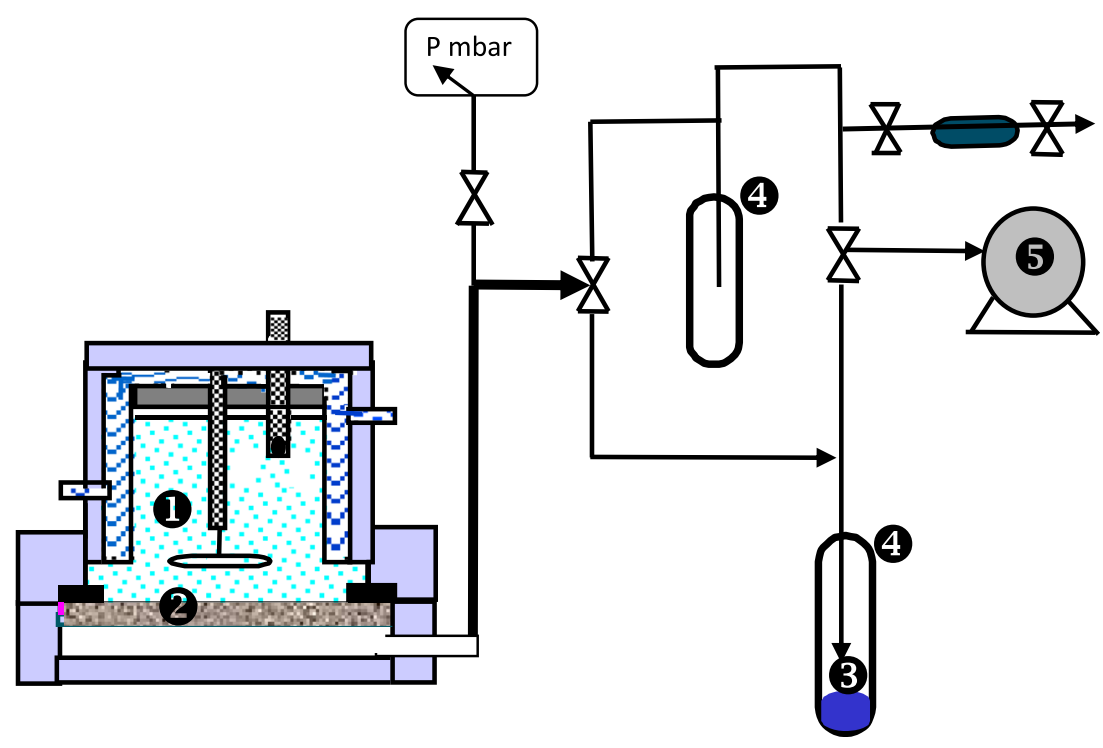

where $y^{\text {vapor }}{ }_{w}$ and $y^{\text {vapor }}{ }_{\text {THF }}$ are the weight fractions of water and THF in the vapor, respectively, and $x_{w}$ and $x_{\mathrm{THF}}$ are the weight fractions of the water and THF in the liquid, respectively.

The calculation of the permeance of the given components requires knowledge of the related driving force. The driving force, which is the partial vapor pressure here, was calculated from the VLE data obtained from Aspen plus software, and the data for the total pressures were used for the permeance calculations.

The membrane permeance $P / l$ (GPU), which is the flux normalized to the driving force, was calculated according to the recommendations of R.W. Baker et al. (2010) to provide useful data for further simulation:

$\frac{P}{l}=\frac{j_{i}}{p_{\text {if }}-p_{i p}}$

where the subscript $i$ represents either water or THF, $l$ indicates the membrane thickness, $j_{i}$ is the partial flux of the $i$ th component, and $p_{i f}$ and $p_{i p}$ are $i$ th component vapor pressures of the feed and permeate, respectively. The permeance data are reported in units of GPU (1 GPU $=1 \times 10^{-6} \mathrm{~cm}^{3}(\mathrm{STP}) / \mathrm{cm}^{2} \mathrm{~s} \mathrm{~cm} \mathrm{Hg} ; 1 \mathrm{~m}^{3} \mathrm{~m} /$ $\mathrm{m}^{2} \mathrm{~s} \mathrm{kPa}=1.33 \times 10^{8}$ GPU).

Each measurement was performed at least three times, and the average value was recorded for later analysis. The mean accuracy for the transport parameters were as follows: for a dense membrane, $\pm 0.2 \%$ for selectivity and $\pm 8 \%$ for flux; for supported membranes, $\pm 0.2 \%$ for selectivity and $\pm 5 \%$ for flux.

\section{Activation energy}

The activation energy for permeation was estimated using the Arrhenius type equation (Sajjan et al. 2013b):

$X=X_{0} \exp \left(\frac{-E_{x}}{R T}\right)$

where $X$ represents permeation (flux $J$ or permeance $P$ ), $X o$ is a constant representing the pre-exponential factor of $J o$ or Po. Ex represents the activation energy for permeation depending on the considered transport process and $R T$ is the usual energy term. To calculate the activation energy, the Arrhenius plots of $\ln J$ and $l n P / l$ versus $1 / T$ were constructed and presented in section below.

\section{Results and discussion}

Therefore, incorporating fullerenol and dispersed nanoparticles is a good approach for tuning the PVA matrix properties. These novel supported membranes with an active layer approximately 30 times thinner" than previously reported were developed and tested for the first time for the separation of binary water-THF mixtures.

\section{Water-THF separation by pervaporation}

The transport of small molecules through polymer membranes is sensitive to polymer modification. The transport properties of the PVA-fullerenol membranes were studied during the separation of the azeotropic composition (94.3 wt\% THF and $5.7 \mathrm{wt} \%$ water) by pervaporation. 


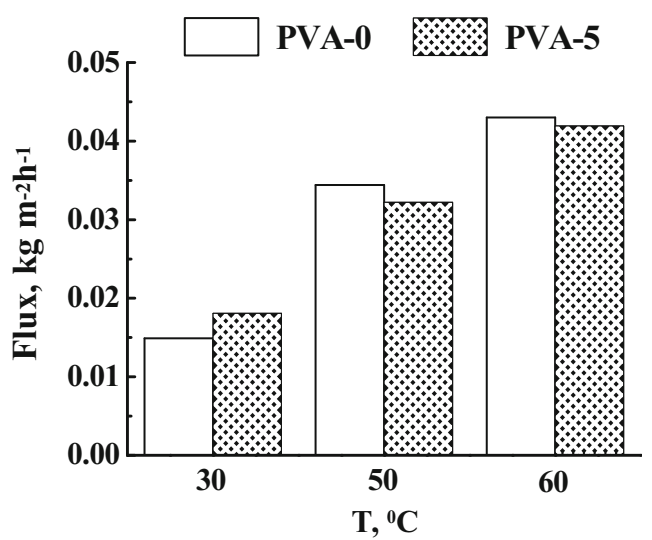

Dense membranes make it possible to accurately characterize the transport properties of the chosen PVA polymer and PVAfullerenol composite because the effect of a support and the defects in the selective layer can be excluded.

Figures 2, 3, and 4 show the results of the water-THF mixture pervaporation using chemically cross-linked membranes of pure PVA (PVA-0-dense) and its mixed matrix containing $5 \mathrm{wt} \%$ fullerenol (PVA-5-dense). For the separation of a $5.7 \mathrm{wt} \%$ water and $94.3 \mathrm{wt} \%$ THF mixture, the permeate exhibited a high water content at $30^{\circ} \mathrm{C}$ that was always higher than that of $99 \%$ water; these results exemplify the need for the preparation of defect-free and selective PVA-based dense membranes.

Figure 2 shows that the water content for the PVA-5-dense membrane was similar to or even higher than that of the pure PVA-0-dense membrane, which demonstrated the positive effect of fullerenol on membrane selectivity due to changes in the inner structure of the dense layer during modification. This figure also shows that the amount of water in the permeate decreased as the temperature increased for the pure PVA and the modified PVA membranes. However, relatively high separation was obtained regardless of the temperature used.

Figure 3 shows the dependence of the membrane flux on the temperature during the water-THF mixture separation using dense membranes in the pervaporation.

For both membrane types, the flux increased as the temperature increases. At this stage in the analysis, this result can be attributed to two factors: (1) high driving forces due to the higher partial pressures of water (water is the most permeable component, while the influence of the THF is negligible) and (2) enhanced membrane permeability.

The results at low temperatures could be explained by two factors that act in opposite directions: (1) the amount of amorphous part, which increases the swelling ability and (2) the cross-linking degree, which reduces the swelling ability. In reference (Penkova et al. 2015), fullerenol was shown to be

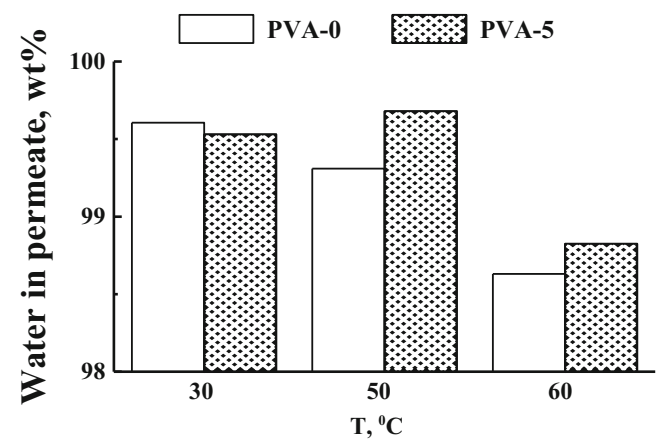

Fig. 2 Dependence of the water content in the permeate on the temperature $\left(30,50\right.$, and $\left.60{ }^{\circ} \mathrm{C}\right)$ during the pervaporation of a $5.7 \mathrm{wt} \%$ water and $94.3 \mathrm{wt} \%$ THF mixture using PVA-0-dense and PVA-5-dense membranes (accuracy $\pm 0.2 \%$ )

Fig. 3 Dependence of the flux on the temperature $\left(30,50\right.$, and $\left.60{ }^{\circ} \mathrm{C}\right)$ during the pervaporation process with a $5.7 \mathrm{wt} \%$ water and $94.3 \mathrm{wt} \%$ THF mixture using PVA-0-dense and PVA-5-dense membranes (accuracy $\pm 5 \%$ )

able to penetrate crystalline regions and cause amorphization that induced a higher swelling degree and flux; this finding can explain the increase in the flux and the slight decrease in the selectivity of the modified membranes compared to those based on pure PVA at lower temperatures.

In order to better understand the effect of temperature, the variations in the permeance should be considered. The flux normalized to the driving force was calculated to consider the dependence of the vapor pressure on the temperature and the activity coefficients and to analyze the transport characteristics of the membranes. The driving force can easily be calculated based on the feed concentrations and the permeate pressures. In many published studies, only the parameters describing the membrane flux and the separation factor are commonly reported; however, these single parameters are of limited interest because they do not allow any modeling or process simulation. Conversely, the pervaporation results, which are reported as permeances, allow further exploitation.

The dependence of the water permeance on the temperatures for the dense membranes is shown in Fig. 4.

The permeance curves in Fig. 4 show that the intrinsic permeance marginally decreases as the temperature increases

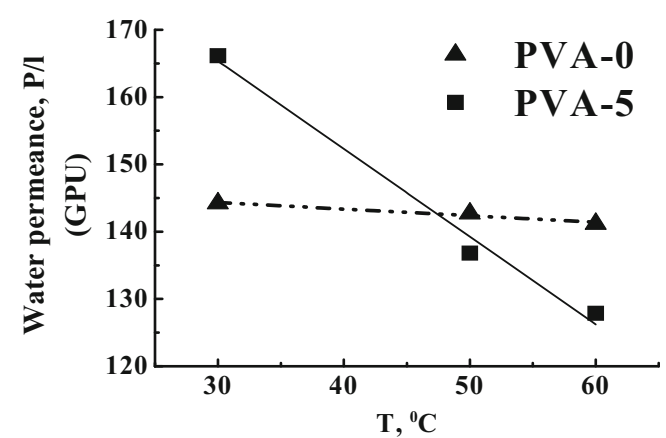

Fig. 4 Dependence of the water permeance on the temperature $(30,50$, and $60{ }^{\circ} \mathrm{C}$ ) during the pervaporation of a $5.7 \mathrm{wt} \%$ water and $94.3 \mathrm{wt} \%$ THF mixture using PVA-0-dense and PVA-5-dense membranes 
for the modified membranes, which reveals an opposite trend from the flux results (Fig. 3). It is well known that permeance can be related to sorption and diffusion phenomena; thus, the temperature effect can be understood as follows: the diffusivity coefficient always increases as the temperature increases, whereas the sorption can decrease or remain constant with temperature due to the polymer network interactions with the permeant species.

Thus, the negative slope indicates that the permeability of the membranes is limited by the sorption, which outweighs the increase in diffusion due to the increased temperature. Two possible explanations can be given for these findings: (1) the water sorption in the membrane is exothermic and (2) the sorption of the polymer network is strongly limited by crosslinking due to the MA and fullerenol, which limits any further increase in the driving force.

\section{Water-THF azeotrope breaking with supported membranes}

To use the PVA selective properties with respect to water in a real industrial process, high flux membranes must be prepared. Thus, a supported membrane with a thin dense layer was developed to ensure high-performance pervaporation at the industrial scale. The mixed matrix supported membrane consisted of a thin, selective PVA top layer with a thickness of approximately $1.5 \pm 0.3 \mu \mathrm{m}$ deposited onto a UPM ultrafiltration porous support, which provides good mechanical strength and does not limit the downstream side of the penetrant mass transport. The SEM micrographs of the cross section of the supported membranes with PVA-0-sup and containing fullerenol were similar. Figure 5 shows a cross section of the PVA-5-sup membrane. The SEM micrograph shows a uniform structure in the dense PVA-fullerenol top layer and also shows that a portion of the porous UPM support exhibited a spongy structure. In addition, this figure shows the excellent adhesion of the selective top layer to the porous support. Based on the SEM data, the thickness of the top layer is found to be equal to approximately $1.8 \mu \mathrm{m}$.

The transport properties of the PVA and PVA-fullerenol (12-5\%) supported membranes were studied during pervaporation of a $5.7 \mathrm{wt} \%$ water and $94.3 \mathrm{wt} \%$ THF mixture. The results are presented in Table 2 and Figs. 6 and 7.

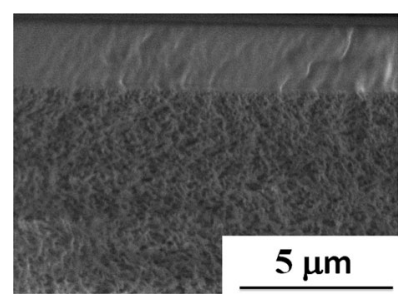

Fig. 5 SEM micrograph of the cross-section of the PVA-5-sup membrane
Table 2 Pervaporation of $5.7 \mathrm{wt} \%$ water and $94.3 \mathrm{wt} \%$ THF mixture with PVA supported membranes at different temperatures

\begin{tabular}{llll}
\hline Membrane & \multicolumn{3}{l}{ Water content in the permeate, wt\% } \\
\cline { 2 - 4 } & $30{ }^{\circ} \mathrm{C}$ & $50{ }^{\circ} \mathrm{C}$ & $60{ }^{\circ} \mathrm{C}$ \\
\hline PVA-0-sup & 97.9 & 98.9 & 99.1 \\
PVA-1-sup & 99.9 & 99.7 & 99.4 \\
PVA-2-sup & 99.5 & 99.4 & 99.7 \\
PVA-5-sup & 99.3 & 98.9 & 99.2 \\
\hline
\end{tabular}

Table 2 presents the data on the water content in the permeate after pervaporation of the water-THF mixture.

The set of data given in Table 2 show that the mean selectivity of the mixed matrix membranes is higher than that of the pure PVA membrane for 1 and $2 \mathrm{wt} \%$ fullerenol; however, increasing the fullerenol content to $5 \mathrm{wt} \%$ produces a slight decrease in the selectivity along with a higher flux.

The effect of temperature on the pervaporation fluxes is shown in Fig. 6. The fluxes clearly increase with temperature for all of the membranes. The membranes modified by fullerenol showed a higher flux than the parent PVA membrane; this can be explained by the higher swelling of the modified membranes due to the incorporation of the nanofullerenol particles, which decreases the crystallinity of the PVA matrix, as previously reported (Penkova et al. 2015).

Figure 7 shows the water permeances calculated from the flux data obtained with the supported membranes.

The general trend observed in these data is similar to the results obtained for the dense membranes: the modified membranes exhibit a decrease in water permeance as the temperature increases, and the slopes of the permeance curves increase with increasing fullerenol content in the membrane. Comparatively, the pure PVA membrane shows the smallest decrease in the water permeance, as was previously observed for the dense PVA-0-dense membrane.

Thus, it has been shown that the supported PVA membranes produce a significant increase in flux without any loss in water selectivity.

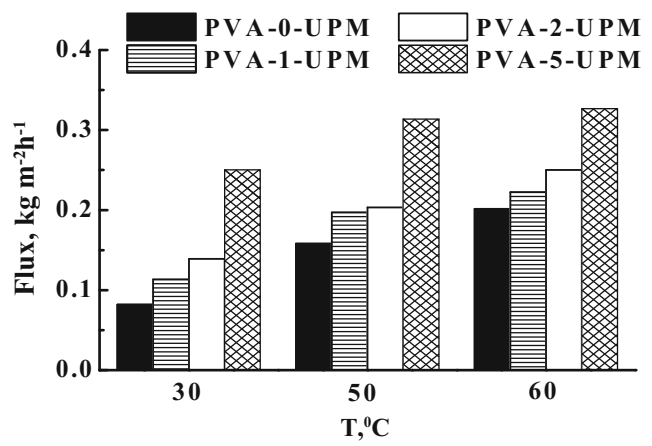

Fig. 6 Dependence of the flux on temperature $\left(30,50\right.$, and $\left.60{ }^{\circ} \mathrm{C}\right)$ during the pervaporation of a $5.7 \mathrm{wt} \%$ water and $94.3 \mathrm{wt} \%$ THF mixture using PVA-0-sup, PVA-1-sup, PVA-2-sup, and PVA-5-sup membranes 


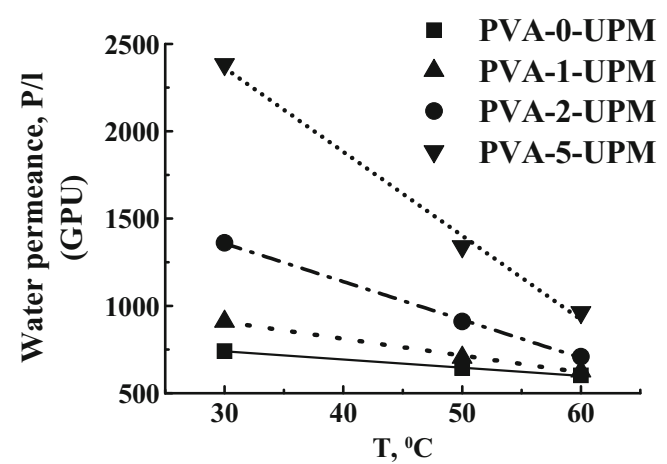

Fig. 7 Dependence of the water permeance on temperature $(30,50$, and $60{ }^{\circ} \mathrm{C}$ ) during the pervaporation of a $5.7 \mathrm{wt} \%$ water and $94.3 \mathrm{wt} \% \mathrm{THF}$ mixture using PVA-0-sup, PVA-1-sup, PVA-2-sup, and PVA-5-sup membranes

\section{Energy of activation}

The effect of the operating temperature on the pervaporation performance was studied for all of the membranes with $5.7 \mathrm{wt} \%$ water in the feed. As expected with an increase in the driving force, the permeation rate was found to increase from 30 to $60{ }^{\circ} \mathrm{C}$ for all of the membranes, whereas the

(a)
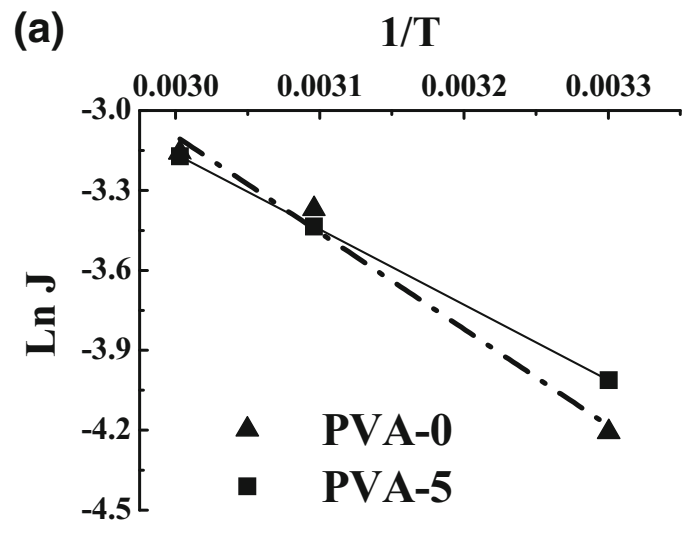

(c)

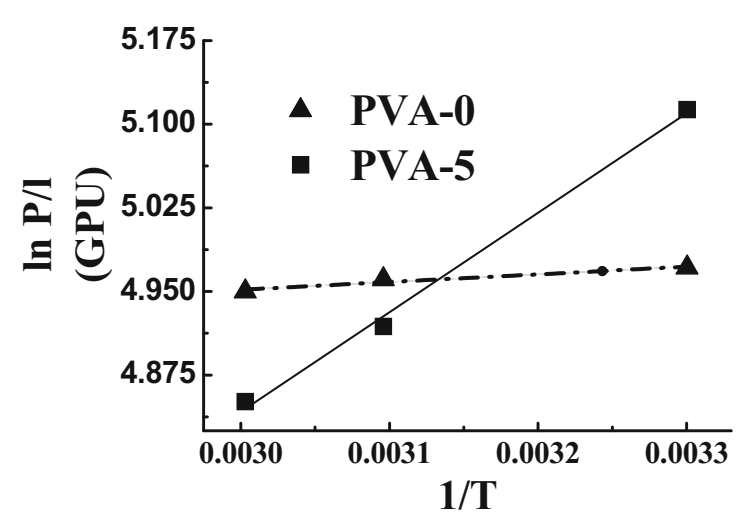

permeance and separation selectivity decreased. Based on the obtained permeation results, the activation energy $(E x)$ for the permeation process was calculated using the Arrhenius equation (Sajjan et al. 2013a), as shown in Eq. (6), which allows for accurate modeling and simulation processes. Ex was calculated according to two approaches. In the first approach, the variation of $\ln J$ with temperature was analyzed to compare data with other results, similar to the process used in the majority of the published papers in which this dependence for Ex calculation was used (Fig. 8, Table 3). The second approach corresponds to analyzing the variation in ln $P / l$ with temperature; the Ex containing fullerenol from this dependence can be used to compare membranes at a constant driving force (Fig. 8, Table 3).

A linear behavior was observed, suggesting that the permeability follows an Arrhenius trend. From the least squares fit of these linear plots, the activation energies for the permeability (Ep) were calculated.

The Arrhenius plots of $\ln J$ and $\ln P / l$ versus $1 / T$ are shown in Fig. 8 for the temperature dependence of the permeation flux.

The values of the activation energy for the membranes tested are presented in Table 3 .

(b)

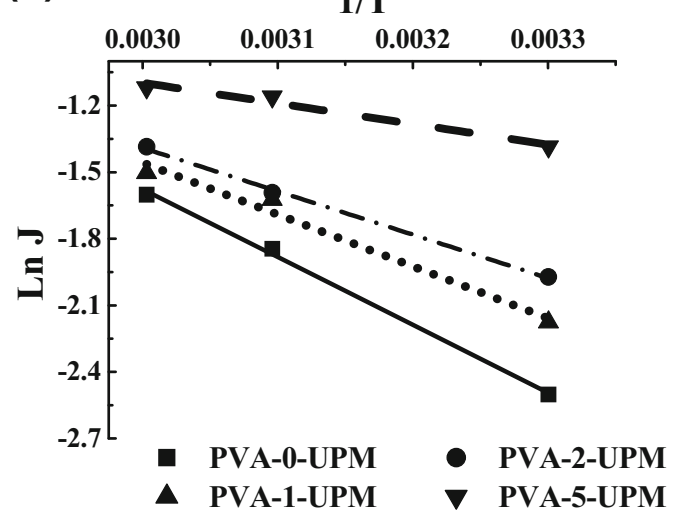

(d)

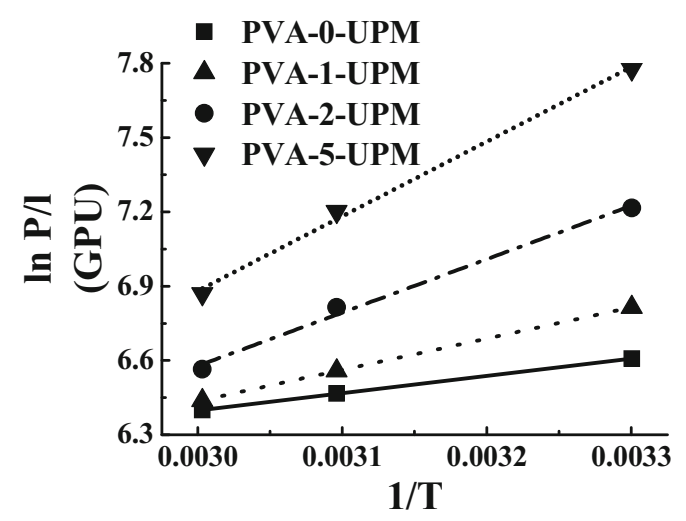

Fig. 8 Variation in $\ln J$ with temperature for dense (a) and supported (b) membranes at $5.7 \mathrm{wt} \%$ water in the feed. Variation in $\ln P / l$ with temperature for dense (c) and supported (d) membranes at $5.7 \mathrm{wt} \%$ water in the feed 
Table 3 Energy of activation calculated for flux and permeance for dense and supported membranes

\begin{tabular}{lll}
\hline Membrane & $E_{\mathrm{J}}, \mathrm{kJ} / \mathrm{mol}$ & $\mathrm{Ep}, \mathrm{kJ} / \mathrm{mol}$ \\
\hline PVA-0-dense & 30.4 & -0.6 \\
PVA-5-dense & 23.5 & -7.4 \\
PVA-0-sup & 25.4 & -5.8 \\
PVA-1-sup & 19.4 & -10.5 \\
PVA-2-sup & 16.2 & -17.9 \\
PVA-5-sup & 7.7 & -25.0 \\
\hline
\end{tabular}

Table 3 shows that the activation energies calculated from the flux for both membrane types decreased as the fullerenol content in the membrane increased due to the lower amount of crystalline areas present. This result suggests a lower activation barrier for the mass transfer of low molecular weight penetrants through the membranes containing fullerenol, whereas the activation energies calculated from the permeances show the opposite trend. This difference can be explained by the two factors (sorption and cross-linking) that were described in the "Water-THF azeotrope breaking with dense membranes" section.

\section{Stability of PVA supported membrane with $5 \%$ fullerenol (PVA-5-sup)}

The above results show that the selectivity of dense and supported membranes remains steady up to $60{ }^{\circ} \mathrm{C}$ (Fig. 2, Tab. 2) for the azeotrope mixture. However, in a hybrid process that combines distillation and pervaporation, the outlet of the distillation column will have a higher amount of water to save energy; reaching the azeotrope point would require both a high reflux ratio and a column with more plates. Thus, it was important to determine whether the thin PVA layers of the supported membranes would be stable with a higher concentration of water in the feed. This section reports the experiment that was conducted to address this concern.

The stability of the PVA-5-sup membrane was studied because this membrane exhibits the highest flux and a high selectivity. The transport properties of the PVA-5-sup membrane were studied for binary water-THF mixtures up to $30 \mathrm{wt} \%$ water in the feed at $30{ }^{\circ} \mathrm{C}$. The pervaporation results are presented in Fig. 9.

Figure 9 shows the total flux and the water content in the permeate; both vary with the composition of the feed with definite regularity. The permeability of the membrane increases with increasing water content in the feed, whereas the water content in the permeate decreases. Pervaporation leads to an opposite enrichment compared to that under VLE; this confirms the strong interest in these membranes for breaking the THF azeotrope due to the high selectivity water transport and also highlights the reason for the industrial interest in these membranes. Figure 9 shows that the VLE

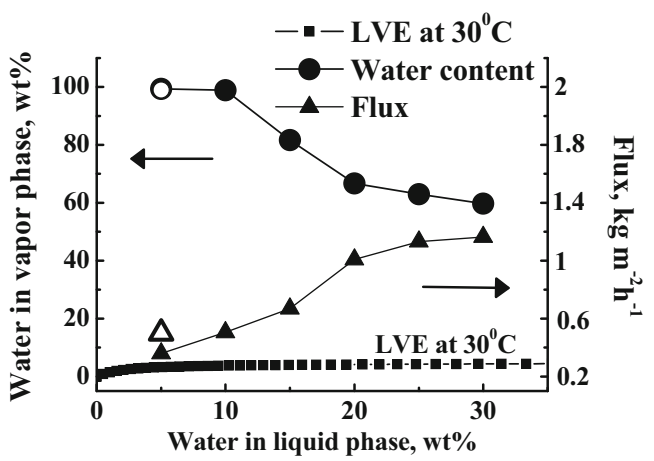

Fig. 9 Dependence of the water concentration in the permeate (dots) and flux (triangles) on the water concentration in the feed during the pervaporation of a water-THF mixture through the PVA-5-sup membrane at $30^{\circ} \mathrm{C}$. The filled symbols demonstrate the membrane properties during the experiment as the water content in the feed increases from $5 \%$ to $30 \mathrm{wt} \%$, and the empty symbols show the membrane parameters after this set of experiments for the initial 5\% water-95\% mixture to evaluate the membrane resistance after exposure to high water concentration. The VLE was calculated using Aspen software

curve is approximately straight in the concentration range examined (e.g., 5 to $30 \mathrm{wt} \%$ water).

Finally, after exposure to a feed water content of up to $30 \mathrm{wt} \%$, the performance of the PVA-5-sup membrane was measured again during the separation of a $5 \%$ water- $95 \%$ THF mixture to determine whether a hysteresis effect was present. The result after only $1 \mathrm{~h}$ of separation is indicated on the pervaporation curve by a white dot (99.0 wt \% water). As shown in this experiment, the membrane performance, which was measured at only $5 \mathrm{wt} \%$ water, is similar to the previously obtained result (99.4 wt\% water): as expected, the selectivity increases to nearly $99 \%$, while the flux drops significantly. Thus, it can be concluded that despite exposure to a feed mixture of up to $30 \mathrm{wt} \%$ water, the transport properties of the supported membrane seem to be rapidly restored. Finally, it should be recalled that $\alpha^{\mathrm{VLE}}$ is equal to 0.62 for the $5 \mathrm{wt} \%$ water in the feed, whereas $\alpha$ pervaporation equals 3045 ( $t=30{ }^{\circ} \mathrm{C}$ for the azeotropic feed), showing the high performance of the membrane.

\section{Conclusion}

Novel chemically cross-linked, PVA-based supported membranes containing up to $5 \mathrm{wt} \% \mathrm{C}_{60}(\mathrm{OH})_{12}$ were prepared with dense selective layers with thicknesses of $\approx 1.5 \mu \mathrm{m}$ to provide high membrane permeance along with high water selectivity. For the first time, the transport properties of the mixed matrix dense and supported membranes were evaluated during the separation of water-THF mixtures in the azeotropic range with concentrations of up to $30 \mathrm{wt} \%$ water in the feed. It was found that all membranes were essentially permeable and selective to water, 
which corresponds to the opposite trend of the water-THF VLE, which indicates that the observed permeate enrichment is not linked to the higher volatility of the THF but is instead effectively linked to the selective transport of water through the membrane. These results confirm the industrial potential of these membranes for breaking water-THF azeotropes. Thus, based on the obtained results, the best compromise of the transport properties during the separation of a water-THF mixture via pervaporation was obtained for the supported PVA-5-sup membrane containing fullerenol. This membrane had a permeate enrichment of $99.4 \pm 0.3 \mathrm{wt} \%$ water and a flux of $0.25 \pm 0.02 \mathrm{~kg} /\left(\mathrm{m}^{2} \mathrm{~h}\right)$ for the separation of a mixture containing $5 \mathrm{wt} \%$ water and $95 \mathrm{wt} \%$ THF at $30{ }^{\circ} \mathrm{C}$. As mentioned in the introduction, based on a previous review (Bradley et al. 2010), the most selective membrane based on the ratio of PVA/chitosan of $20: 80$ had a permeate enrichment of 99.55 and a flux of $0.098 \mathrm{~kg} /\left(\mathrm{m}^{2} \mathrm{~h}\right.$ ) (Rao et al. 2007) for a feed mixture of $5 \mathrm{wt} \%$ water and $95 \mathrm{wt} \%$ THF at $30{ }^{\circ} \mathrm{C}$. Therefore, the PVA-5-sup membrane showed an improved flux and a high level of selectivity. Moreover, the method of membrane preparation is simple and "green." Including fullerenol nanoparticles in the PVA matrix significantly improved the membrane performance due to the nanoscale modifications of the PVA dense polymer structure. To investigate the potential applications of this membrane in a process designed to dehydrate THF with a pervaporation step, the performance and stability of the supported membrane were studied. The results showed that the PVA-5-sup membrane is stable over a wide range of water contents in the water-THF feed mixture.

Acknowledgements A.V. Penkova would like to thank the Fellowship of the President of Russia CП-1153.2015.1. The authors would also like to gratefully acknowledge the grants of the Russian Foundation for Basic Research No. 15-58-04034, the grants of St. Petersburg State University (No. 12.42.1003.2016) (M.E. Dmitrenko), and the financial support from Région Lorraine (ARCUS 3). This research was partially supported by a grant from the Russian Foundation for Basic Research No. 15-03-02131. The experimental work of this study was facilitated by equipment from the Resource Centers of GEOMODEL, the Chemical Analysis and Materials Research Centre, and the Interdisciplinary Resource Center for Nano Technology at St. Petersburg State University. The authors would also like to gratefully acknowledge Etienne Berger for her help with the Aspen calculations.

\section{References}

Baker RW, Wijmans JG, Huang Y (2010) Permeability, permeance and selectivity: a preferred way of reporting pervaporation performance data. J Memb Sci 348:346-352. doi:10.1016/j.memsci.2009.11.022

Bradley D, Williams G, Lawton M (2010) Drying of organic solvents: quantitative evaluation of the efficiency of several desiccants. J Org Chem 75:8351-8354. doi:10.1021/jo101589h

Chapman PD, Oliveira T, Livingston AG, Li K (2008) Membranes for the dehydration of solvents by pervaporation. J Memb Sci 318:5-37. doi:10.1016/j.memsci.2008.02.061

Koczka K, Manczinger J, Mizsey P, Fonyo Z (2007) Novel hybrid separation processes based on pervaporation for THF recovery. Chem Eng Process 46:239-246. doi:10.1016/j.cep.2006.05.016

Mahdi T, Ahmad A, Nasef MM, Ripin A (2015) State-of-the-art technologies for separation of azeotropic mixtures. Sep Purif Rev 44:308330. doi:10.1080/15422119.2014.963607

Penkova A V, Acquah SFA, Dmitrenko ME, et al (2016) Improvement of pervaporation PVA membranes by the controlled incorporation of fullerenol nanoparticles. Mater Des 96:416-423. doi: 10.1016/j. matdes.2016.02.046

Penkova AV, Acquah SFA, Sokolova MP et al (2015) Polyvinyl alcohol membranes modified by low-hydroxylated fullerenol C-60(OH) 12 . J Memb Sci 491:22-27. doi:10.1016/j.memsci.2015.05.011

Penkova AV, Acquah SFA, Dmitrenko ME et al (2014) Transport properties of cross-linked fullerenol-PVA membranes. Carbon N Y 76: 446-450. doi:10.1016/j.carbon.2014.04.053

Rao KSVK, Subha MCS, Sairam M et al (2007) Blend membranes of chitosan and poly(vinyl alcohol) in pervaporation dehydration of isopropanol and tetrahydrofuran. J Appl Polym Sci 103:19181926. doi:10.1002/app. 25078

Sajjan AM, Jeevan Kumar BK, Kittur AA, Kariduraganavar MY (2013a) Development of novel grafted hybrid PVA membranes using glycidyltrimethylammonium chloride for pervaporation separation of water-isopropanol mixtures. J Ind Eng Chem 19:427-437. doi: 10.1016/j.jiec.2012.08.032

Sajjan AM, Kumar BKJ, Kittur AA, Kariduraganavar MY (2013b) Development of novel grafted hybrid PVA membranes using glycidyltrimethylammonium chloride for pervaporation separation of water-isopropanol mixtures. J Ind Eng Chem 19:427-437. doi:10. 1016/j.jiec.2012.08.032

Servel C, Roizard D, Favre E, Horbez D (2014) Improved energy efficiency of a hybrid pervaporation/distillation process for acetic acid production: identification of target membrane performances by simulation. Ind Eng Chem Res 53:7768-7779. doi:10.1021/ie500467k

Truong HT, Rode S, Roizard D et al (2013) Dehydration of reactive industrial mixtures by pervaporation: an innovative approach in acrylic esters processes. Sep Purif Technol 120:24-34. doi:10. 1016/j.seppur.2013.09.017

Wilkes PR, Scarlett J, Harrison GE (1990) Process for the purification of tetrahydrofuran.

Xu S, Wang H (2006) A new entrainer for separation of tetrahydrofuranwater azeotropic mixture by extractive distillation. Chem Eng Process 45:954-958. doi:10.1016/j.cep.2006.02.001 